\title{
APRECIAÇÃO MUSICAL: REFLEXÕES SOBRE O PROCESSO DE FORMAÇÃO ATRAVÉS DA ESCUTA
}

Leonardo do Nascimento Rodrigues

Doutorando em Música/UNIRIO

lnrodriguest3@gmail.com 


\section{Resumo}

O objetivo deste trabalho é apresentar reflexões sobre formação cultural, hábitos de escuta, gostos e preferências musicais e suas relações com a indústria cultural. Sob um ponto de vista educacional, pretende-se buscar fundamentos filosóficos e sociológicos que possam alicerçar as atividades de apreciação musical com alunos da escola regular. As reflexões sobre indústria cultural foram feitas com base no pensamento de Adorno (1941; 1996), Adorno e Horkheimer (2002) e Morin (1977) e Bourdieu (1974). Acredita-se que, a partir dessas reflexões, será possível melhor compreender a influência dessa indústria cultural na formação cultural dos alunos, além de contribuir para que o educador tenha maior consciência dessa influência e possa conduzir seus alunos a formas de apreciação musical que transcendam as formas passivas e distraídas de escuta, típicas das músicas de massa, possibilitando assim uma maior fruição estética e artística, estimulando-os a outras maneiras de se relacionar com a música.

Palavras-chave: apreciação musical; escuta musical; indústria cultural; educação musical

\section{Abstract}

The objective of this paper is to present reflections on cultural formation, listening habits, musical tastes and preferences and their relations with the cultural industry. From an educational point of view, we seek to find philosophical and sociological foundations that can support the activities of musical appreciation with regular school students. Reflections on cultural industry were made on the basis of Adorno (1941; 1996), Adorno and Horkheimer (2002) and Morin (1977) and Bourdieu (1974). It is believed that from these reflections it will be possible to better understand the influence of the cultural industry on the cultural formation of the students, besides contributing to the educator being more aware of this influence and can lead his students to forms of musical appreciation that transcend passive forms and distracted from listening, typical of mass music, thus allowing a greater aesthetic and artistic enjoyment, stimulating them to other ways of relating to music.

Keywords: musical appreciation; musical listening; cultural industry; musical education 


\section{Introdução}

Por meio dos seus sentidos, o indivíduo estabelece contato com o mundo exterior e com ele interage, observando, percebendo, analisando os diversos fenômenos e assim vivencia um conjunto de experiências que formarão sua identidade, seu caráter e sua maneira de se comportar perante esse mundo.

A experiência estética costuma ocorrer pela interação desse indivíduo com as mais diversas produções artísticas, e, para que essa experiência ocorra de maneira adequada e enriquecedora é importante que esse indivíduo esteja preparado para vivenciá-la, que tenha desenvolvido as ferramentas de apreensão artística apropriadas, pois somente assim estaria, de fato, apto a assimilar verdadeiramente o material artístico e atribuir-lhe um significado (PENNA, 2008).

Em relação à música, a interação ocorre primeiramente por meio da escuta e essa prática encontra-se presente em todos os estágios do desenvolvimento musical, pois, logicamente, não há fazer musical sem escuta, sendo esta, o início e o fim de todo o processo (SWANWICK, 1978; 2003).

Embora a prática da escuta musical esteja presente e se mostre indispensável em todo o processo de formação e em todo o fazer musical, existe uma forma de escuta específica e direcionada que tem por pretensão ampliar as possibilidades de interação com a música. Essa prática, chamada apreciação musical, mostra-se de grande alcance no processo de formação musical, pois permite desenvolver no aluno-ouvinte novas posturas diante de conteúdos musicais diversos, posturas mais conscientes, ativas e concentradas, possibilitando novas maneiras de perceber o fenômeno sonoro e os aspectos artístico/musicais a ele inerentes (SWANWICK, 2003; GRANJA, 2006).

O presente texto foi inicialmente produzido no decorrer de uma pesquisa de mestrado sobre apreciação musical, que culminou na dissertação intitulada "Apreciação Musical nos anos iniciais do Ensino Fundamental: experiências de escuta de música instrumental” (RODRIGUES, 2017), para a qual foi desenvolvida uma pesquisa sobre escuta musical de obras instrumentais com uma turma de $3^{\circ}$ ano do ensino fundamental. Buscou-se nesta investigação, entre outras coisas, observar como os alunos se sentiriam e se comportariam ao apreciarem música instrumental e, sobretudo, investigar se a prática regular da apreciação musical poderia levá-los a desenvolver maior interesse por esse tipo 
de música, o qual, os próprios alunos demonstraram não possuir familiaridade nem costume de escutar no dia a dia.

Para o desenvolvimento desta pesquisa, considerou-se fundamental, primeiramente, que fossem desenvolvidas reflexões sobre hábitos de escuta e formação cultural, alicerçados em autores que discutem o fenômeno da indústria cultural atualmente talvez melhor entendida pelo termo "mídia" -, e a sua interferência direta na formação musical e cultural das pessoas, tornando possível melhor compreender a formação do "gosto" musical e identificar a maneira com que geralmente ocorrem as relações dessas pessoas com a música.

Para refletir sobre aspectos ligados à escuta e a influência das mídias, são apresentadas as seguintes questões: o que de fato levaria os alunos a preferirem determinados tipos de música em detrimento de outros? Os hábitos de escuta desses alunos seriam desenvolvidos de forma autônoma e espontânea, ou simplesmente seriam frutos de uma imposição das mídias de massa? De que maneira a educação musical poderia contribuir para a autonomia e liberdade de escolha musical do aluno e para formação de um gosto verdadeiramente pessoal?

As reflexões e as respostas a essas questões serão buscadas tomando por base o pensamento de filósofos como Adorno (1941; 1996), Adorno e Horkheimer (2002) e Morin (1977) e Bourdieu (1974), que se dedicam parte de sua obra a explicar as razões pelas quais a sociedade tende muitas vezes a valorizar as formas de produção artística mais comerciais, e muitas vezes ignorar os valores genuínos da sua própria cultura e da cultura universal.

\section{Fundamentação Teórica}

O papel da escuta musical na formação cultural do indivíduo

Se é principalmente por meio da $\operatorname{escuta}^{1}$ que o indivíduo estabelece contato com o universo musical, sua prática deveria ser mais enfatizada nos

\footnotetext{
${ }^{1}$ Granja (2006) considera que "escutar é um processo mais elaborado que ouvir". Segundo o autor "Ouviré captar fisicamente a presença do som [...] Escutar, por outro lado, é dar significado ao que se ouve. Em poucas palavras, poderíamos dizer que o ouvir refere-se ao conforto do previsível, enquanto o escutar
} 
processos de formação em música, como considera Swanwick (2004), que em seu modelo TECLA ${ }^{2}$ atribui à apreciação musical um papel de destaque dentro dos itens considerados indispensáveis a uma aula de música. Inúmeros outros autores como o compositor Aaron Copland (1974) e pesquisadores como Del Ben (2007), Granja (2006), Bastião (2009), Boal-Palheiros \& Hardgreaves (2003) atestam a importância e a eficiência de um trabalho de educação musical tendo como suporte a escuta atenta, reflexiva e direcionada.

O termo apreciação musical, deve aqui ser entendido como prática que objetiva estimular e desenvolver nos alunos uma escuta musical ativa, promover experiências que permitam uma ampliação de seus repertórios, suas referências de gêneros e linguagens musicais, bem como refletir e compreender melhor o que escutam em seus cotidianos.

Partindo dessa ideia geral de apreciação musical, construída a partir de conceitos de alguns desses autores supracitados, formulou-se a hipótese de que a apreciação musical seria um instrumento adequado para promover uma "transformação" na forma de escutar música dos alunos. Através dela, os estudantes poderiam expandir suas habilidades de escuta concentrada e interessada, melhor assimilar linguagens musicais que lhe são menos familiares, e até mesmo desenvolver interesse por elas.

Embora esses autores deixem claro a importância da prática da apreciação musical no processo de formação cultural do indivíduo e alguns até mesmo proponham abordagens e atividades de escuta, há ainda inúmeros pontos importantes a serem discutidos, que vão além das questões puramente educacionais, devendo ser tratados sob uma ótica filosófica e sociológica, de modo a melhor compreender a maneira como as pessoas vem se relacionando

demanda uma predisposição para a acuidade sonora”. (GRANJA, 2006, p. 65 grifos nosso). E é com esses sentidos que os termos escutar e ouvir deverão ser entendidos para o presente texto.

2 - A sigla TECLA representa um modelo metodológico proposto por SWANWICK (1979) que considera as atividades de Técnica, Execução, Composição, Literatura e Apreciação como os itens indispensáveis em uma aula de música. (N.A) 
com a música na sociedade contemporânea e quais mecanismos estão por trás de seus hábitos de escuta.

Primeiramente, é preciso contextualizar e refletir sobre as atuais práticas de escuta musical dos alunos. Em função da forte presença das mídias de massa, sobretudo a internet e a televisão, torna-se infrutífera qualquer reflexão sobre apreciação musical e educação que não leve em consideração a realidade inconteste da influência desses veículos na forma como os alunos "percebem" a música e a cultura e a forma como com elas se relacionam.

É fato que esses veículos vêm abrindo, e cada vez mais, um leque quase infinito de possibilidades de acesso à música. Com a popularização da internet e dos canais de TV a Cabo, especializados em shows e videoclipes, as pessoas em geral se veem diante de uma simultaneidade de estímulos ao consumo de modismos e tendências musicais. Sobretudo os jovens, que se sentem, muitas vezes, atraídos e dominados por conteúdos amplamente difundidos pelas mídias, sem que façam uma reflexão em torno do conteúdo por elas oferecido, quase sempre de forma unilateral, e sem que conheçam de fato, outros repertórios e possibilidades de apreciação da música.

A fim de refletir sobre as práticas de escuta musical na atualidade, seus problemas e suas possibilidades, é importante considerar todo um corpo teóricofilosófico que vem sendo produzido ao longo de décadas. Vários filósofos e pensadores trataram de inúmeras questões ligadas à indústria cultural, à cultura de massas e à mercantilização da música, ou seja, à maneira como o objeto artístico-musical vem, cada vez mais, sendo tratado como simples mercadoria a ser consumida. Essas questões, inevitavelmente, influenciam os processos de escuta e as relações dos ouvintes com a música na atualidade.

Um dos pensadores mais conhecidos e que mais se dedicaram a tais questões foi Theodor W. Adorno (1903 - 1969) - filósofo alemão e um dos principais integrantes da chamada Escola de Frankfurt - que, em sua vasta produção filosófica, dedicou parte de seus escritos a reflexões em torno da indústria cultural, fetichização da música, regressão nas formas de audição 
musical (tema de grande importância para o presente trabalho) e ainda sobre educação e problemas na formação cultural dos indivíduos (teoria da semiformação), temas esses de grande valor para os estudos sobre a formação pela e para a escuta.

\section{2 - A decadência do gosto}

Logo no início de seu célebre texto O Fetichismo da Música e a Regressão da Audição, Adorno já desconsidera a ideia de "gosto pessoal", denunciando sua decadência. Para ele, o próprio conceito de gosto estaria ultrapassado, não havendo mais campo para a escolha, visto que não se poderia mais chamar de "gosto" algo que na verdade seria meramente fruto de uma "imposição" da indústria cultural:

Se perguntarmos a alguém se "gosta" de uma música de sucesso lançada no mercado, não poderemos furtar-nos à suspeita de que o gostar e o não gostar já não correspondem ao estado real (...) Em vez do valor da própria coisa, o critério de julgamento é o fato de a canção de sucesso ser conhecida de todos (ADORNO, 1996, p. 66)

Para esse pensador, a decadência do gosto se justifica pela perda da individualidade, uma vez que o indivíduo, como ser autônomo, deixou de existir, tornando-se apenas parte da massa que obedece cegamente à moda musical de seu tempo, criada e imposta pelas mídias. Sendo assim, se não há individualidade, não há uma escolha pessoal de fato.

Já não há espaço algum para o indivíduo, cujas exigências são ilusórias, ou seja, forçadas a se moldarem aos padrões gerais (...). A liquidação do indivíduo constitui o sinal característico da nova época musical em que vivemos (ADORNO, 1996, p. 73). 
Essa perda da individualidade seria decorrente da produção padronizada dos bens de consumo, a chamada estandardização, oferecendo às pessoas os mesmos produtos, levando todos a fazerem as mesmas coisas, a usufruírem dos mesmos bens de consumo.

Entretanto, se o indivíduo liquidado aceita realmente e com paixão a exterioridade consumada das convenções como critério, deve-se dizer que a época áurea do gosto irrompeu num momento em que não há mais gosto algum (ADORNO, 1996, p. 80).

O autor observa que tudo é muito semelhante na cultura contemporânea, sendo possível perceber uma homogeneização nos vários planos da cultura e da sociedade. O processo de "nivelamento cultural" seria fruto do controle das massas pelo "capital" e pelo sistema articulado por detrás do mesmo, fazendo com que "necessidades iguais sejam satisfeitas com produtos estandardizados" (ADORNO, 2002, p.6).

Em outro trabalho, Sobre Música Popular (1941), Adorno demonstra que a estandardização tem como intuito proporcionar uma fácil familiarização da música pelo ouvinte, por meio de formas pré-estabelecidas e padrões harmônicos recorrentes, garantindo que "o hit acabará conduzindo tudo de volta para a mesma experiência familiar, e que nada de fundamentalmente novo será introduzido" (ADORNO, 1941, p. 116). Para ele, essa seria a característica fundamental da música popular e um dos pontos em que difere da música séria.

No entanto, para assegurar o sucesso de suas produções, a indústria cultural se utiliza de outro mecanismo, aparentemente contraditório, que envolve oferecer um produto estandardizado e que, ao mesmo tempo, apresente aspectos de novidade, para que assim seja aceito, como afirma Morin (1977):

A indústria cultural deve, pois, superar constantemente uma contradição fundamental entre suas estruturas burocratizadas-padronizadas e a originalidade (individualidade e novidade) do produto que ela deve fornecer (MORIN, 1977, p. 25). 
Diante dessas afirmações, e de modo a entender todo o processo, é possível observar uma cadeia de ocorrências que vem contribuindo para estabelecer a atual forma de escuta musical das massas. Essa cadeia está estruturada da seguinte maneira: a estandardização leva à perda da individualidade, que leva à decadência do gosto e, consequentemente, à sua ausência, culminando em uma escuta musical limitada e problemática, à qual Adorno se refere como audição regressiva.

\section{3 - Audição regressiva}

Segundo Adorno (1996), a audição regressiva é um estágio da escuta musical própria dos ouvintes modernos, em que o indivíduo se encontra condicionado a aceitar de forma passiva a música que lhe é imposta, e, quando resolve "escolher", acaba exigindo novamente o mesmo que lhe foi oferecido, como crianças geralmente fazem. "Os ouvintes e os consumidores em geral precisam e exigem exatamente aquilo que lhes é imposto insistentemente" (ADORNO, 1996, p.89-91). Além disso, o processo de regressão da audição está também ligado a um mecanismo de simplificação da música, a sua adaptação a uma linguagem "infantilizada”, que garanta o fácil entendimento e a aceitação das massas, e que, no entanto, impedem-na de evoluir, de passar para um estágio seguinte, de maior amadurecimento, pois "a audição infantil requer sempre as soluções mais cômodas e comuns" (ADORNO, 1996, p. 97).

Os ouvintes, vítimas da regressão, comportam-se como crianças. Exigem sempre de novo, com malícia e pertinácia, o mesmo alimento que uma vez lhes foi oferecido (...). Para tais ouvintes, elabora-se uma espécie de linguagem musical infantil, que se distingue da linguagem genuína porque o seu vocabulário consta exclusivamente de resíduos e deformações da linguagem artística musical (ADORNO, 1996, p. 96)

E ainda, essa forma de audição caracteriza-se pela alternância constante entre esquecimento e reconhecimento e "constata-se uma regressão quanto à 
possibilidade de uma outra música, oposta a essa" (ADORNO, 1996, p. 90). A razão de tal fenômeno atingir a sociedade e sua maneira de se relacionar com a música seria, sobretudo, a forma como a música vem sendo produzida e difundida, que leva a "infantilização" da apreensão musical. "A audição regressiva relaciona-se manifestadamente com a produção, através do mecanismo de difusão, o que acontece precisamente mediante a propaganda" (ADORNO, 1996, p. 90).

Esse parece ser um fenômeno bastante presente na atual forma de escuta musical das pessoas, sobretudo pela grande quantidade de hits lançados ininterruptamente pela indústria cultural. Esses hits, que geralmente obedecem a "fórmulas de sucesso", acabam por se limitarem a uma pequena diversidade de gêneros, sendo as mídias (rádio, televisão e internet) as responsáveis por essa propagação unidimensional que, ao mesmo tempo em que manipula as massas, impondo o que deverá ser apreciado, utiliza-se dessa demanda criada por ela mesma para lançar novos hits e assim perpetuar um círculo vicioso que se retroalimenta. No entanto, Morin (1977) levanta a seguinte questão: "a cultura de massa é imposta do exterior ao público ou reflete as necessidades do público?" (MORIN, 1977, p.47). Às vezes se torna impossível saber se de fato a indústria cultural se utiliza das massas ou o contrário. $O$ fato é que se trata de um fenômeno que muitas vezes impede essa massa de uma transcendência cultural, de reconhecer outros valores e ir além do que é estabelecido por esse sistema.

Dentro da problemática da regressão da audição, Adorno (1996) discute ainda, de forma mais específica, a maneira desconcentrada com que as massas escutam a música da atualidade, pois, já que não se trata mais de gosto pessoal, mas de puro modismo, essa seria a única maneira de se escutar tal música sem que ela se torne insuportável.

O modo de comportamento perceptivo, através do qual se prepara o esquecer e o rápido recordar da música de massas, é a desconcentração. Se os produtos normalizados e irremediavelmente semelhantes entre si, exceto certas particularidades surpreendentes, não permitem uma audição 
concentrada sem se tornarem insuportáveis para os ouvintes, estes, por sua vez, já não são absolutamente capazes de uma audição concentrada (ADORNO, 1996, p. 92).

O entretenimento provocado pela "nova" música é uma via de mão dupla: ao mesmo tempo em que provoca distração e prazer, leva à perda da capacidade de comunicação. A música passou a ser utilizada como fundo para outras atividades e já não se escuta mais de forma concentrada, mas de maneira passiva e distraída. (ADORNO, 1996, p.66-67)

No texto Sobre Música Popular, o pensador trata ainda da distração e desatenção na escuta, porém, denunciando ser esse fenômeno próprio da música popular, por esta cumprir o papel de puro entretenimento, utilizada para aliviar as massas das pressões impostas pelo trabalho e ajudar-lhes a repor as energias antes de voltarem à atividade produtiva. Devido a isso, esse tipo de música é geralmente ouvido de forma distraída e desatenta, pois a demanda desse público é de "um relaxamento que não envolva nenhum esforço de concentração" (ADORNO, 1941, p. 137)

No entanto, essa função de entretenimento da música popular pode dar uma falsa impressão de a mesma ser benéfica às massas, mas, na verdade, o que o autor se propõe a mostrar é que a indústria cultural se aproveita desta "carência" da classe trabalhadora para ganhar popularidade e estabelecer-se.

\section{4 - A indústria cultural}

Indústria cultural é um termo criado por Theodor Adorno e Max Horkheimer - este último também importante filósofo da Escola de Frankfurt para designar o mecanismo de "coisificação" da arte e da cultura, que vem transformar a música, o cinema e as artes visuais em produtos destinados a simples consumo e entretenimento das massas na sociedade capitalista. Esse sistema busca ainda estabelecer hábitos de consumo para esses bens culturais 
produzidos por ele mesmo, utilizando-se largamente da técnica e dos meios de difusão cultural. (HORKHEIMER, Max; ADORNO, Theodor, 2002).

Para conceituar esse movimento, surgido a partir da primeira metade do século XX e produzido "segundo as normas maciças da fabricação industrial” , Morin (1977) utiliza o termo Cultura de Massas em vez de Indústria Cultural, referindo-se a ela como uma Terceira Cultura- "oriunda da imprensa, do cinema, do rádio, da televisão- que surge, desenvolve-se e projeta-se, ao lado das culturas clássicas, religiosas, humanistas e nacionais”. (MORIN, 1977, p14).

No entanto, independente dos termos, o mais importante para este trabalho é compreender de que forma o estabelecimento de uma Indústria Cultural (ou Cultura de Massas) implicaria na fruição artística das massas e no reconhecimento dos valores culturais.

A respeito disso, Morin (1977) contribui com a seguinte afirmação:

Enfim, a orientação consumidora destrói a autonomia e a orientação estética próprias da cultura cultivada (...). O produto cultural está estritamente determinado por seu caráter industrial de um lado, seu caráter de consumação diária de outro, sem poder emergir para a autonomia estética (MORIN, 1977, p. 18).

Os interesses mercadológicos se sobrepõem às diretrizes artísticas, visando atingir às grandes massas e, consequentemente, garantir o lucro financeiro. Essa maneira com que o capital trata os bens culturais termina por atingir diretamente as relações das massas com esses bens, pois, se não há estímulo para a fruição estética, e somente para consumo e entretenimento, o indivíduo dificilmente conseguirá reconhecer a autonomia das artes (dança, música, artes visuais, cinema etc.), seus próprios valores artísticos e culturais.

No caso específico da música, presume-se que esse fenômeno da indústria cultural interfira de maneira avassaladora na forma como a massa vem se relacionando com a mesma, e no modo de apreciá-la. Se os mecanismos de difusão cultural (rádio, televisão, internet) estimulam quase que somente a escuta 
unidimensional, de uma música comercial e estandardizada, é até compreensível que as pessoas se vejam distantes e desinteressadas de apreciarem outros estilos de música que não sejam aqueles oferecidos por esse "monopólio cultural".

5 - A semiformação e possíveis saídas para o problema da escuta musical

Uma das possíveis causas para essa audição descomprometida encontra-se na própria formação geral do indivíduo. Em seu texto "Teoria da semicultura", Adorno aponta os problemas na formação cultural das massas, resultantes de uma educação geralmente limitada, voltada não para o desenvolvimento da autonomia e a liberdade das pessoas, mas para o preparo delas para o "mercado de trabalho", em uma dinâmica constante de produção e consumo.

Diante dessas condições impostas pelos interesses do capitalismo, a sociedade muitas vezes reconhece pessoas como "bem sucedidas" somente por terem alcançado determinado status social e econômico, sem levar em consideração seu nível geral de formação cultural. Muitos indivíduos "formados" dentro desse panorama apresentam inúmeras deficiências em seu processo de desenvolvimento intelectual; seu preparo técnico-acadêmico é voltado quase que exclusivamente para sua área de atuação, sem estímulo ao desenvolvimento de sua sensibilidade para o reconhecimento de valores da cultura universal, ou da sua própria cultura. Esse fenômeno é o da chamada semiformação, conforme defendido por Adorno (1974).

A semiformação, presente em praticamente todos os estratos da sociedade, mostra-se, inclusive, como uma estratégia sagaz para o controle das massas, mantendo-as "cegas", alienadas e vulneráveis a manipulações diversas. Através da semiformação, o capital mantém sob seu controle tanto os "diplomados" - os "doutores" tão reverenciados pelo senso comum, que, como já foi dito, são geralmente formados de maneira parcial, apenas dentro do âmbito de sua profissão - quanto à classe operária, que normalmente dispõe de menores condições de acesso aos estudos. Desse modo, torna-se possível assegurar que a 
massa - formada não por base nas condições econômicas, mas pelo nível de alienação e dependência - seja ao mesmo tempo produtora e consumidora, dispondo poucas condições críticas para se opor ao sistema econômico implantado.

Essa teoria mostra ainda que, por muito tempo, as formas de dominação capitalista destituíram a classe trabalhadora do acesso aos bens culturais e ao ócio, tempo disponível necessário para sua formação cultural, e essa desigualdade entre as classes tentou ser compensada pela implantação de uma educação popular, que logo se mostrou insuficiente para reverter a situação (ADORNO, 1996, p.3). Assim, o proletariado, que esteve por muito tempo excluído do acesso à formação, passa a ter que usufruir de um conteúdo cultural "ajustado" a sua condição, perpetuando assim essa realidade (ADORNO, 1996, p. 3).

$\mathrm{O}$ autor citado aponta ainda a contradição existente entre a ideia de formação e os modelos adotados pelos sistemas de ensino, pois, se formação pressupõe autonomia, estaria então impedida de se realizar:

A formação tem como condições a autonomia e a liberdade. No entanto, remete sempre a estruturas pré-colocadas a cada indivíduo em sentido heteronômico e em relação às quais deve submeter-se para formar-se. Daí que, no momento mesmo em que ocorre a formação, ela já deixa de existir. Em sua origem está já, teleologicamente, seu decair (ADORNO, 1996, p. 5)

Bourdieu (1974) reforça essa ideia, pois, para ele, o sistema educacional seria mais um mecanismo de legitimação cultural através da imposição, apresentando uma dinâmica interna de "seleção" dos conteúdos e assuntos a serem difundidos e ensinados e, consequentemente, consagrados, em detrimento a outros aspectos, que na maioria das vezes são ignorados, esquecidos:

Toda ação pedagógica define-se como um ato de imposição de um arbitrário cultural (...) o sistema de ensino cumpre inevitavelmente uma função de legitimação cultural ao converter em cultura legítima (...) o 
arbitrário cultural que uma formação social apresenta pelo mero fato de existir e, de modo mais preciso, ao reproduzir, pela delimitação do que merece ser transmitido e adquirido e do que não merece (BOURDIEU, 1974, p. 120).

Dessa maneira, a crise da formação cultural não seria um problema apenas de ordem pedagógica; inclusive as inovações nesse setor seriam ineficientes para impedi-la. Assim, são necessárias melhores reflexões e investigações acerca dos "fatores sociais que interferem positiva ou negativamente na formação cultural" (ADORNO, 1996, p. 1).

Se o problema da formação cultural está, antes de tudo, ligado a fatores sociais, e se a educação se mostra, muitas vezes, veículo de afirmação da semicultura, dever-se-ia pensar práticas educacionais de escuta musical capazes de romper com a realidade que se apresenta, aliando o pensamento didático e pedagógico às questões socioculturais. Assim, é necessário, primeiramente, reconhecer as experiências e vivências musicais dos alunos, levando-os a uma reescuta de seus repertórios, em busca de reflexões para, então, introduzir outros conteúdos musicais que levem esse público a uma experiência musical mais profunda e abrangente.

Mas quais seriam, de fato, esses "outros conteúdos"? Qual seria a música adequada para o trabalho de apreciação musical na educação básica brasileira? Diante de tudo que foi discutido até este ponto, somos levados a entender primeiramente que não se deve simplesmente tentar sobrepor uma nova realidade musical à anterior. Inclusive, é importante evitar inicialmente fazer "juízos de valor" em relação aos "gostos" musicais dos alunos. A questão não é simplesmente substituir uma coisa pela outra, mas estimular esses alunos a desenvolverem novas referências musicais, expandindo seus horizontes sonoros e permitindo melhores condições de formação de seus repertórios de gêneros musicais, estilos, artistas etc. Que a educação possa contribuir para esse processo de formação, não deixando isso somente a cargo dos veículos de difusão, ou melhor, das mídias.

Para isso, o professor educador musical poderia trabalhar sobre dois aspectos da formação pela escuta: como escutar e o que escutar. 
O primeiro deles, como escutar, trata de técnicas e procedimentos para a apreciação, como por exemplo, sentar-se em postura confortável, fechar os olhos, escutar com atenção, descrever as sensações provocadas pela música; ou então, escutar e expressar-se por meio de movimentos corporais ou através de ilustrações, entre inúmeras possibilidades. Seja qual for a abordagem de escuta, é preciso ter sempre em mente a busca pela reflexão e atribuição de sentido à música apreciada. Para isso, é fundamental que o professor contextualize a música, tanto antes quanto após a escuta, orientando seus alunos quanto a aspectos diversos ligados à obra, como o momento histórico de sua produção, a cultura à qual pertence, a instrumentação utilizada, e até mesmo aspectos "mais musicais" como características rítmicas e melódicas.

O segundo ponto, o que escutar, relaciona-se diretamente ao repertório, ao material musical a ser apreciado pelos alunos. Os critérios para seleção devem estar bem definidos, pois, se a intenção é ampliar o conhecimento dos alunos sobre música - gêneros, estilos, artistas etc. - o exercício da escuta deve abranger a música do cotidiano dos próprios alunos, para uma troca de experiências e, principalmente, para uma reflexão sobre o que vêm ouvindo; a música oriunda das manifestações musicais da sua própria cultura, buscando reconhecê-la como tal; a música de outras culturas e regiões, como forma de perceber as diferenças existentes; a música puramente instrumental, como, por exemplo, o jazz, o choro, ou releituras instrumentais de canções já conhecidas; e obras da tradição musical ocidental, a chamada música erudita, devido ao seu valor universal atemporal, de modo a que sejam conhecidas produções musicais do passado, e o que vem sendo produzido pelos compositores contemporâneos.

Importante ressaltar que para atingir os objetivos de ampliação do repertório e do universo musical dos alunos, é preciso, antes de tudo, partir de um critério básico de seleção do material de escuta: o de priorizar a apreciação de gêneros e estilos musicais que usufruam de menor espaço nas mídias (a música instrumental ou canções folclóricas ao invés do sertanejo universitário ou funk carioca, por exemplo). Se a indústria cultural estimula incessantemente o 
consumo de determinados segmentos musicais - e excluindo aqueles tidos como "menos comerciais" - caberia ao professor buscar inverter essa realidade, reservando um espaço maior para o trabalho de apreciação dos outros gêneros, geralmente marginalizados por esses veículos. A sala de aula não pode ser o ambiente para a simples afirmação dos hábitos de escuta já existentes, mas um espaço que estimula e permite que, de forma autônoma e consciente, os estudantes se libertem e interajam com todo um universo musical existente, ou ao menos com uma parcela maior deste.

\section{Considerações Finais}

Acredita-se que para desenvolver um trabalho de Educação Musical, por meio da apreciação musical, é importante que o educador tenha consciência do poder de influência que essas mídias podem vir a ter sobre a formação dos "gostos", preferências e hábitos de escuta de seus alunos. A partir disso, o docente deveria buscar meios para alargar suas percepções e seus leques de referências musicais por meio de atividades e práticas que visem levar o aluno a transcender essa condição que, muitas vezes, lhe é imposta pela cultura de massas.

No entanto, é fundamental deixar claro que o intuito de alicerçar a prática da apreciação musical nos pensamentos desses autores não é o de simplesmente buscar "combater" a influência dessas mídias, ou desconsiderar a bagagem musical dos alunos obtida por meio dela. O objetivo primeiro é ter consciência do impacto que esses mecanismos podem vir a ter na formação cultural do indivíduo e, sobretudo, enxergar esses hábitos e as relações estabelecidas por meio desses como passíveis de alargamento. Inclusive, essa cultura musical de massas pode servir como um importante ponto de partida para que o aluno venha despertar para toda uma variedade musical existente, variedade esta que muitas vezes esses mecanismos da cultura massiva omitem do grande público.

Isso, inclusive, se fez valer na pesquisa de mestrado anteriormente citada, quando os alunos foram levados a não somente apreciar as obras musicais sugeridas pelo professor, mas também estimulados a trazer para a sala de aula as músicas que gostavam, a fim de que pudessem ser apreciadas por toda turma, de modo a conhecerem os gostos 
musicais uns dos outros e respeitarem as diferenças de gêneros e estilos musicais por cada um preferidos. Essa foi uma das formas encontradas de valorizar e considerar as bagagens musicais desses alunos e também de estimulá-los a se colocarem em posição mais receptiva a outros repertórios, menos familiares, trazidos para a sala de aula pelo professor.

Sob a ótica dos autores que fundamentaram este texto, respondendo à primeira das questões lançadas inicialmente, o que levaria os alunos a preferirem determinados tipos de música em detrimento de outros seria a forma como ocorre a veiculação do "produto musical”, que pela incessante difusão e repetição nos veículos de comunicação, acaba por levar grande parte do público a tomar conhecimento desse "produto", se familiarizar com o mesmo e - de forma quase inevitável - a ele se identificar. As "fábricas de hits", inclusive, já possuem as fórmulas prontas para isso, pois já conhece seu público, que fora por ela mesma moldado, e já sabe como preparar novos hits, visando atender a "demanda" desse público, "demanda" muitas vezes criada por essa própria indústria.

Apesar dos autores mencionados e suas teorias serem oriundos do contexto do século XX, é possível enxergar, na atualidade, muitas coisas que estes já apontavam no passado, inclusive de forma muito mais intensa, articulada e refinada.

Como exemplo temos, no Brasil, o fenômeno midiático e comercial do gênero “sertanejo universitário", que, há quase uma década, domina as paradas de sucesso no país. Esse fenômeno se mostra uma boa maneira de entender como a indústria cultural funciona e como esta se adaptou ao contexto do século XXI, época da comercialização de shows em DVD's, dos downloads e compartilhamento de arquivos mp3, e da popularização dos serviços de streaming, como Youtube e Spotify.

As estratégias para lançamentos de novos artistas e de novos hits se mostram cada vez mais sofisticadas, indo desde a produção de dezenas de músicas com temáticas clichês e com a mesma progressão harmônica (sobretudo a já desgastada progressão I V - vi - IV) - em um exemplo claro do fenômeno da "audição regressiva”, apontada há décadas por Adorno - ao apelo audiovisual, priorizando o lançamento de registros ao vivo, em formato audiovisual (DVD's, Blu-Rays, e também vídeos em plataformas online como Youtube) em detrimento de trabalhos de estúdio - onde a superprodução visual de figurinos e cenários chegam a se sobressair sobre o conteúdo musical. 
Sobre outra questão lançada: se hábitos de escuta desses alunos seriam desenvolvidos de forma autônoma e espontânea, ou simplesmente seriam frutos de uma imposição das mídias de massa? A própria pesquisa realizada demonstrou que os alunos são sim, influenciados de inúmeras formas pela mídia, pois suas preferências musicais demonstram reproduzir aquilo que é amplamente difundido por esses canais de comunicação. Mas não somente isso: demonstram também serem influenciados pelos hábitos de escuta musical de familiares e de pessoas próximas - incorporando em seus repertórios, inclusive, músicas não atuais, escutadas por essas pessoas - e pela cultura musical religiosa, quando esses alunos participam de alguma manifestação religiosa.

Esses fatores demonstram que a mídia - ou indústria cultural - de fato, tem participação preponderante na formação dos gostos musicais dos alunos, mas estes se mostram receptivos também a outras influências. Isso leva a acreditar que se os alunos “aprendem a gostar" de músicas conhecendo-as muitas vezes através de uma escuta mais passiva - por meio da mídia ou de "terceiros" - um trabalho de apreciação musical de forma ativa em sala de aula, conduzida de maneira apropriada, poderia obter desses alunos respostas ainda mais significativas.

Dessa maneira, escola e educador musical poderiam se tornar também uma dessas influências, interferindo positivamente no sentido de levar os alunos a conhecerem gêneros musicais e obras que, via de regra, são omitidos pelos grandes veículos. Isso possibilitaria que o professor promovesse, além da ampliação dos repertórios musicais dos alunos, certo equilíbrio entre a escuta dos "hits do momento", oferecidos pela mídia, e a apreciação de outros materiais musicais, oriundos de outras tradições como da música de concerto, da música popular urbana ou rural, ou de manifestações culturais de contextos específicos.

Dessa maneira, acredita-se que o aluno possa perceber todos esses universos musicais - midiático, erudito, popular, de matrizes socioculturais específicas - como igualmente apreciados, de formas particulares, permitindo que o discente tenha, de fato, oportunidades de conhecer essas expressões musicais e saber em que medida essas lhe agrada ou não, e diante disso, fazer suas próprias escolhas.

A fim de que o trabalho de educação musical possa contribuir para a autonomia e liberdade de escolha musical do aluno e para formação de um gosto verdadeiramente pessoal, parece necessário o professor propor a seus alunos outras formas de escuta do repertório que lhe é familiar e também a escuta de outros repertórios, sendo essa uma 
possível forma de ressignificar o que já lhe é usual e proporcionar condições para que possam encontrar seus próprios significados em obras musicais e gêneros diversos, e que possam vir a fazer parte de seu "cardápio musical".

Diante de tais reflexões entende-se ser um dos papeis do educador musical o de - por meio de um trabalho de apreciação - sensibilizar seus alunos para valores estéticos, artísticos e socioculturais que uma obra musical pode trazer consigo, levandoos a descobrirem por si mesmos o prazer e a satisfação de novas formas de escuta. Que estes possam perceber que por meio de uma escuta ativa, atenta e reflexiva é possível mergulhar em um universo de relações sonoras, afetivas e de significados diversos, os quais farão parte do seu ser e de sua percepção do mundo.

\section{Referências}

ADORNO, Theodor. O fetichismo na música e a regressão da audição. São Paulo: Círculo do Livro, 1996.

ADORNO, Theodor W; HORKHEIMER, Max. O Iluminismo como mistificação das massas. In: Indústria Cultural e Sociedade. São Paulo: Paz e Terra, 2002.

ADORNO, T. W. \& SIMPSON, G. Sobre Música Popular. In: Horkheimer, Max, ed. Studies in philosophy and social Science. Nova York, 1941.

ADORNO, Theodor W. Teoria da semicultura. In: Revista Educação e Sociedade n. 56, ano XVII, dezembro de 1996, pág. 388-411.

BASTIÃO, Zuraida A. A abordagem AME - Apreciação Musical Expressiva - como elemento de mediação entre teoria e prática na formação de professores de música. Dissertação (mestrado em música) - Universidade Federal da Bahia, Salvador; 2009.

BOAL-PALHEIROS, G; HARGREAVES, D. Modos de ouvir música em crianças e adolescentes. In: Cuadernos Interamericanos de investigación en Educación Musical. Vol. 3 N5. Universidad Nacional Autónoma de México, México DF; 2003. 
BOURDIEU, Pierre. O mercado dos bens simbólicos. In: A economia das trocas simbólicas. (org. Sérgio Miceli). São Paulo: Perspectiva, 1974. P. 99-181.

COPLAND, Aaron. Como ouvir (e entender) música. Trad. Luiz Paulo Horta. Artnova; 2013. Rio de Janeiro: 1974.

RODRIGUES, Leonardo N. Apreciação Musical nos anos iniciais do ensino fundamental: experiências de escuta de música instrumental. Dissertação (mestrado em música) - Universidade Federal do Estado do Rio de Janeiro. Rio de Janeiro, 2017.

MORIN, Edgar. Cultura de massas no século XX: o espírito do tempo - I. Neurose. Rio de Janeiro: Forense Editora, 1977.

PENNA, Maura. Música e seu(s) ensino(s). Editora Sulina: Porto Alegre, 2009. 